oxygen." More objectionable still are occasional instances of bogus reasoning, the most striking example being an erroneous proof of the conservation of mass. On three different occasions the indestructibility of matter is stated to be a consequence of the law of definite proportions. Almost equally bewildering is an attempt to show that " a molecule occupies two volumes," an attempt which even when correctly carried out might well be excluded from a book which professes to discourage anything akin to cramming. No advance is made in familiarizing the learner with accurate conceptions of atom and molecule; indeed the need for the latter conception in chemical philosophy is quite overlooked.

Throughout the book the author's mode of expressing himself is frequently not the happiest. To say that "air allows all bodies that will to take fire in it," or that "chlorine does not combine with an excess of hydrogen" is harmless enough perhaps. On the other hand to talk of the "properties of a mixture" being the "sum of the properties of its constituents," or of the gas being kept dissolved in a bottle of soda water "by the pressure of the cork," or to say that "water has weight and exerts pressure "cannot but be puzzling to the intelligent reader.

To prepare a thoroughly good introduction, of the most elementary kind, to the study of chemistry, is a work of considerable difficulty, indeed it is one which few of our leading chemists seem desirous of undertaking. Enough we think has been quoted from the book under notice to show that the author has by far underrated the difficulty of this task.

J. W. R.

\section{LIFE AND DEATH.}

Essai sur la Vie et la Mort. Par Armand Sabatier. (Paris: Babé et Cie.)

PROF. SABATIER'S “Essai sur la Vie et la Mort" forms the fourth volume of the "Bibliothèque Évolutioniste," a series of books published under the direction of M. de Varigny, with the view of expounding in a strictly scientific manner the different principles and the diverse applications of the theory of Evolution. The series most appropriately begins with a translation of Wallace's "Darwinism," and it is gratifying to our national pride to find that the two other works which have as yet appeared in the series, Ball's " Treatise on Use and Disuse," and Geddes' and Thomson's "Evolution of Sex," as well as the two others announced as in the press, are all by British authors.

The present essay, which extends over $280 \mathrm{pp}$., is the outcome of a series of lectures delivered at the University of Montpellier. It is written in a clear, simple style, devoid for the most part of all technicalities which appeal only to the specialist. The problems of life and death are dealt with from an exclusively biological point of view, and questions of morality and theology are hardly touched upon. It is difficult to do justice to the views expounded in the book in the short space at our disposal, but an attempt may be made to give a short account of its contents. The first part deals with life : the properties of living matter are considered in great detail, and Prof. Sabatier endeavours to show that the attributes of life are found to some extent, at any rate, in dead matter. According to his views "la matière brute est vivante aussi," but the manifestations are slow and dull. To the Professor's mind living matter and dead matter are not absolutely distinct: between the two states of matter there is only a difference of degree and not of kind. "La vie donc est partout, dans la matière dite inanimée comme dans la matière vivante." The various features in which dead matter behaves like living, are considered at great length; but, curiously enough, no mention is made of Buitschli's remarkable experiments on artificial amœbæ, recently described in the "Quarterly Journal of Microscopical Science."

This view being accepted, death in the ordinary sense of the word, naturally cannot exist, and the phenomenon which we usually call death becomes but another form of life-_" la vie intense" simply passes into the state of "la vie lente." Immortality, according to our author, consists in the indefinite continuity of life ("la vie intense") without arrest or interruption. Like Weismann, he maintains that the negation or the contrary of such immortality involves the presence of a dead body or corpse. Weismann holds that ciliated infusoria are immortal if kept under favourable conditions, these conditions, of course, including frequent opportunities of conjugating. Sabatier considers that such infusoria are only potentially immortal, and that the act of conjugation converts this potentiality into a real immortality. In his opinion the primitive protoplasm was immortal, and the habit of dying has been acquired by the higher organisms in response to two stimuli, one internal and one outside themselves. The internal cause of death is associated with a tendency innate in the living being to improve its position in the world, in response to which it has become more specialized, and developed new organs and powers. This specialization has borne with it the seeds of death. The external cause is the surrounding world, which constantly stimulates and promotes the organism to new efforts, and in the struggle for the mastery death is brought about.

Although we fail to see that Prof. Sabatier has thrown any new light upon the problems he attempts to solve, and although the explanations he advances seem to us inadequate, his book is a useful one, inasmuch as he gives us a careful summary of the numerous views advanced by various writers in the last twenty-five years, on the subject of life and death, and criticises with considerable ability the theories of Weismann, Goette, Minot, \&c. In fact, his destructive powers seem greater than his constructive.

A. E. S.

\section{OUR BOOK SHELF.}

Contagious Foot Rot in Sheep. By Prof. G. T. Brown, C.B., I6 pp., 8 illustrations, (John Murray).

THIS pamphlet is a reprint from the second part of 1 the current volume of the Royal Agricultural Society's Journal. A few additional remarks on the prevention of foot rot have been added, and if the instructions given were fully carried out, the disease would soon cease to be troublesome. The preventive suggestions are (I) separation from the rest of the flock for one month of all animals newly purchased; and (2) isolation of all animals affected.

In discussing the treatment of the disease, Prof. Brown

$$
\text { NO. I I98, VOL. 46] }
$$

